\title{
Antioxidative and Inhibition Potency of Cynodontin
}

\author{
Jelena Đorović $^{{ }^{*}}$, Marko Antonijević ${ }^{1}$, Zoran Marković ${ }^{1,2}$ \\ ${ }^{1}$ Department of Science, Institute for Information Technologies, University of Kragujevac, \\ Jovana Cvijića bb, 34000 Kragujevac, Republic of Serbia \\ e-mail: jelena.djorovic@uni.kg.ac.rs,mantonijevic@uni.kg.ac.rs, zmarkovic@uni.kg.ac.rs \\ ${ }^{2}$ Department of Chemical-Technological Sciences, State University of Novi Pazar, Vuka \\ Karadžića bb, 36300 Novi Pazar, Serbia \\ e-mail: zmarkovic@np.ac.rs \\ *corresponding author
}

\begin{abstract}
The antioxidant activity of cynodontin was studied in the absence and the presence of free radical species. This in silico study was performed in water and benzene, with the aim to simulate polar and non-polar environment. To determine the most probable mechanism of antioxidant action, density functional theory (DFT) was employed. The change in reaction enthalpy of cynodontin with three different free radicals (hydroxyl, hydroperoxyl, and methyl peroxyl radical) were examined and presented. SET-PT (Single Electron Transfer - Proton Transfer) mechanism is not an operative mechanism of antioxidant action. The obtained results imply that the possible mechanism of antioxidant action in water is SPLET (Sequential Proton Loss Electron Transfer), while in benzene HAT (Hydrogen atom transfer) and SPLET are competitive mechanisms. The molecular docking study was performed in order to estimate the inhibition potency of the investigated compound toward human leukocyte elastase (HLE). The obtained results indicate that numerous interactions determine the inhibition activity towards the investigated protein.
\end{abstract}

Keywords: cynodontin, antioxidative mechanisms, molecular docking simulations

\section{Introduction}

Free radicals and various reactive chemical species are constantly generated in the human metabolic system. Oxygen is essential for aerobic organisms, although it creates reactive oxygen species (ROS). When the amount of reactive chemical species exceeds the capacity of the endogenous antioxidative protection system, the organism is found in the state known as oxidative stress (OS). Damage induced by oxidative stress can be reduced using natural and synthetic compounds widely recognized under the term antioxidants. Molecules of antioxidants retain the ability to form relatively stable chemical species after scavenging of free radicals. Investigating characteristics of antioxidants is of high interest in the prevention of various diseases that are considered to be, at least partially, caused by oxidative stress, such as cancer, inflammation, hypertension, and cardiovascular disorders (Halliwell et al, 1999; Halliwell, 
2001a). Numerous neurodegenerative disorders, in the first place Alzheimer's and Parkinson's diseases, can also have a basis in oxidative stress (Halliwell, 2001b). Nevertheless, the behavior of antioxidants in various radical scavenging processes has not been completely explained. Compounds that are considered as good antioxidants often possess some properties such as low toxicity, availability, versatility, optimal reactivity, high regeneration, and ability to cross physiological barriers (Rose et al., 1993; Galano, 2015). Each of these qualities needs to be evinced; otherwise, antioxidant is not suitable for usage. In terms of toxicity, it is important that good antioxidants should not be toxic, either before or after the radical scavenging. Furthermore, an efficient antioxidant should be in an adequate concentration in cells. When we talk about versatility, it is considered that a good antioxidant should be able to easily react with different free radicals. One of the main characteristics of good antioxidants is fast radicalscavenging reactions. In other words, they need to react fast enough with radicals to prevent them from reacting with biological material that they are supposed to protect. Moreover, good antioxidants need to be able to pass physiological barriers so they can be transported to cells where they are needed the most. Particularly efficient in reducing OS are antioxidants that have physiological mechanisms to regenerate their original form because they can inactivate more than one radical.

Initially, all colorants were obtained from the natural sources: plants, lichens, insects, or shellfish. Anthraquinones are a group of natural compounds predominant and represented by the red dyes kermes from the insect Kermococcus ibicish, (Thomson, 1971) cochineal from the dried bodies of Dactylopius coccus cacti, (Gordon et al., 1983) lac from the insect Laccifer lacca Kerr (Taylor, 1986) and Turkey Red formed by complexing alizarin obtained from the root of Rubia tinctorum with a mixture of aluminium and calcium salts. These colorants are good quality, even by modern standards, and cochineal possesses brilliance and fastness attributes that no artificial dye has yet surpassed (Walton et al., 1991). Still, following the work of Perkin (Zollinger, 1987) the attention was focused on the synthetic dyes that have now supplanted the natural ones. The synthetic anthraquinone dyes are the second most significant group of organic colorants registered in the Colour Index. They tend to prevail in the violet, blue, and green hue sectors (Shore, 1990). Special brilliance, high light fastness, and chemical stability, that are challenging to achieve with other chemical compounds, are properties that describe anthraquinone dyes (Annen et al., 1987). Main application groups of anthraquinone dyes are dispersive, vat, and acid dyes, although they are used for the dyeing and printing of all types of textile materials (Renfrew, 1985). Usual conditions for the synthesis of anthraquinones are the use of strong acids at high temperatures and heavy metal catalysts (Booth, 1988), and this results in the production of environmentally inhospitable effluents and hazardous byproducts. With increasing awareness of the damage caused to the environment by industry, the disposal of industrial effluent is becoming more costly and strictly regulated. It is not the intention to return to dyes obtained from the mollusks, insects, fungi or plants grown in their natural habitat because these methods are not practical and, in many ways, may be regarded as environmentally malignant. Various fungi, that produce anthraquinones as secondary metabolites, have the potential to be a source of a dyestu intermediate. This way of obtaining a dye can contribute to the control of malignant effluent and byproduct creation. Fungal anthraquinones as polyketide-derived secondary metabolites and occur widely in many genera of fungi. In comparison with the commercially accessible hydroxyanthraquinones, most of these compounds possess an additional methyl group. Anthraquinone named cynodontin (Fig. 1) can be produced in sufficient purity. That allows it to be modified using a simple chemical step to a dye product, and this compound can be easily comparable with a commercially prepared analog. 


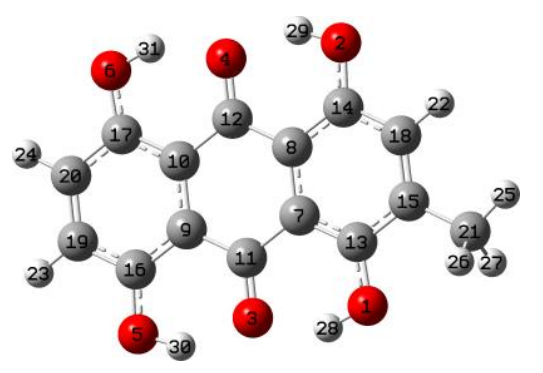

Fig. 1. Optimized and labeled structure of cynodontin

In this study, antioxidative properties of cynodontin (CYN) are investigated, as well as its inhibition potency against human leukocyte elastase (HLE), by means of the Molecular Docking analysis. To examine the interaction of CYN with a protein, SwissTargetPrediction analysis of ligand (Fig. 1) is performed. This analysis predicts the inhibition of HLE by CYN molecule. HLE is a chymotrypsin-like serine protease composed of 218 amino acid residues (Sinha et al., 1987). A synonym for the enzyme is human neutrophil elastase (HNE), reflecting the fact that it is produced by neutrophilic granulocytes, which are the most abundant cells of the innate immune system in human blood. HLE is encoded by the ELANE gene (Takahashi et al., 1988) and it is prohibited from causing proteolytic damage to the connective tissue, which is a particular problem in chronic obstructive pulmonary disease (COPD; Hiemstra et al., 1998).

\section{Theoretical framework}

Various quantum-mechanical approaches can be used to quantify the antioxidant activity (Álvarez-Diduk et al., 2015; Petrović et al., 2015). The reaction between the ROS and antioxidants can follow two different pathways: H-atom abstraction and radical adduct formation (Alberto et al., 2013; Galano et al., 2016). The first process will be investigated and it includes mechanistic pathways that are considered to be different, but in essence, they are similar. It should be pointed out that the outcome of all discussed mechanisms is the formation of the more stable radical species, A-O•. Three different antioxidative mechanisms were studied and reported in this paper (Rimarčík et al., 2010): hydrogen atom transfer (HAT), singleelectron transfer followed by the proton transfer (SET-PT) and sequential proton loss electron transfer (SPLET). The transfer of hydrogen atom from the molecule of antioxidant to radical specie (Eq. 1) defines HAT mechanism. SET-PT is a two-step mechanism: the first step consists of the formation of radical-cation which is the initial specie in the second step of this mechanism (Eqs. 2 and 3). The other mechanism that consists of two-step reactions is the SPLET mechanism. Reactions that illustrate this mechanism are presented with Eqs. 4 and 5. The enthalpies of these processes can be used as the first parameter in the determination of the preferred mechanistic pathway of antioxidative reaction. Generally speaking, HAT is a preferred reaction mechanism in a non-polar medium because it does not involve charge separation. Regarding processes of charge separation that are present in SET-PT and SPLET mechanisms, it can be assumed that these mechanisms will be favored in the polar medium (Zhang et al., 2006).

$$
\begin{gathered}
A-O H \rightarrow A-O+H \\
A-O H \rightarrow A-O H^{++}+e^{-} \\
A-O H^{+} \rightarrow A-O+H^{+}
\end{gathered}
$$




$$
\begin{gathered}
A-O H \rightarrow A-O^{-}+H^{+} \\
A-O^{-} \rightarrow A-O^{-}+e^{-}
\end{gathered}
$$

Thermodynamic parameters that describe those mechanisms are BDE (bond dissociation enthalpy), IP (ionization potential), PDE (proton dissociation enthalpy), PA (proton affinity) and ETE (electron transfer enthalpy). BDE describes the HAT mechanism, while IP and PDE are engaged with the SET-PT mechanism. When the SPLET mechanism is discussed, values of PA and ETE parameters are examined.

BDE, IP, PDE, PA, and ETE values are determined from total enthalpies of the individual species, using the following equations:

$$
\begin{gathered}
B D E=H(A-O)+H(H)-H(A-O H) \\
I P=H\left(A-O H^{+}\right)+H\left(e^{-}\right)-H(A-O H) \\
P D E=H(A-O)+H\left(H^{+}\right)-H\left(A-O H^{+}\right) \\
P A=H\left(A-O^{-}\right)+H\left(H^{+}\right)-H(A-O H) \\
E T E=H(A-O)+H\left(e^{-}\right)-H\left(A-O^{-}\right)
\end{gathered}
$$

The reaction of HAT, SET-PT, and SPLET mechanisms are also being followed when reaction includes free radical species $\left(\mathrm{RO}^{*}\right)$. Reaction with reactive radical species, that follows the HAT mechanistic pathway, is represented by the Eq. (11):

$$
\mathrm{A}-\mathrm{OH}+\mathrm{OR} \rightarrow \mathrm{A}-\mathrm{O}+\mathrm{ROH}
$$

The SET-PT mechanism is the second considered mechanistic pathway of radicalscavenging reactions. It is a two-step mechanism as it is illustrated above, in Eq. 2 and 3, but in interaction with free radicals $\left(\mathrm{RO}^{\circ}\right)$ is occurring following the next equations:

$$
\begin{gathered}
A-\mathrm{OH}+\mathrm{OR} \rightarrow \mathrm{A}-\mathrm{OH}^{+\cdot}+\mathrm{OR} \\
A-\mathrm{OH}^{+\cdot}+\mathrm{OR} \rightarrow A-\mathrm{O}+\mathrm{ROH}
\end{gathered}
$$

Third investigated mechanism of antioxidant action is SPLET. The reaction between the antioxidant and the free radical via the SPLET mechanism can be described by the following reactions:

$$
\begin{gathered}
A-\mathrm{OH}^{-} \mathrm{OR} \rightarrow A-\mathrm{O}^{-}+\mathrm{ROH} \\
A-\mathrm{O}^{-}+\mathrm{OR} \rightarrow A-\mathrm{O}^{-} \mathrm{OR}
\end{gathered}
$$

The reaction of the investigated compound with free radicals is thermodynamically favorable if it is exothermic, and that is determined by changes in reaction enthalpy (Eqs. 16):

$$
\Delta_{r} H=[H(\text { product })-H(\text { reac } \tan t s)]<0
$$

Radical inactivation by the HAT mechanism (Eq. 17) is defined by the H-atom transfer from the examined compounds to the free radical species $\left(\mathrm{RO}^{*}\right)$. Thermodynamic parameter, $\Delta_{r} H_{\mathrm{BDE}}$, can be calculated using the following equation:

$$
\Delta_{r} H_{B D E}=H(A-O)+H(R O H)-H(A-O H)-H(O R)
$$


The SET-PT mechanism is described by usage of thermodynamic parameters that are calculated by applying the following equation:

$$
\begin{gathered}
\Delta_{r} H_{I P}=H\left(A-O H^{+}\right)+H(O R)-H(A-O H)-H(O R) \\
\Delta_{r} H_{P D E}=H(A-O)+H(R O H)-H\left(A-O H^{++}\right)-H(O R)
\end{gathered}
$$

When the antioxidant is reacting with the corresponding free radical via SPLET mechanism, the values of the thermodynamic parameters $\Delta_{r} H_{P A}$ and $\Delta_{r} H_{E T E}$ that are responsible for that mechanism can be calculated using the following equations:

$$
\begin{gathered}
\Delta_{r} H_{P A}=H\left(A-O^{-}\right)+H(R O H)-H(A-O H)-H\left({ }^{-} O R\right) \\
\Delta_{r} H_{E T E}=H(A-O)+H(O R)-H\left(A-O^{-}\right)-H(O R)
\end{gathered}
$$

It can be said that although there is a competition between these mechanistic pathways, the reaction can take place across several of them simultaneously. All mentioned free radical scavenging mechanisms have the same product, and that is stable radical of antioxidant. Because of that, they have the same net thermodynamic balance, Eq. (22).

$$
\Delta_{r} H_{B D E}=\Delta_{r} H_{I P}+\Delta_{r} H_{I P}=\Delta_{r} H_{P A}+\Delta_{r} H_{E T E}
$$

\subsection{Computational methods}

The equilibrium geometries of the parent molecule of cynodontin and corresponding radical cation, radicals, and anions were optimized by the DFT method at M05-2X/6-311++G(d,p) level of theory. The software package Gaussian 09 is used for all calculations (Frisch et al., 2009). The M05-2X functional is a commonly used method and some reasonable results are achieved for thermochemical calculations of organic, organometallic, and biological compounds (Zhao et al., 2008). The local and global minima were confirmed (no imaginary frequencies were obtained). The CPCM solvation model is applied to evaluate the impact of polar and non-polar solutions (water and benzene) (Takano et al., 2005). The values for solvation enthalpies of proton and electron are taken from the literature (Tošović et al., 2016). In equations are used reaction enthalpies calculated at $298 \mathrm{~K}$.

The molecular docking simulations are carried out using the AutoDock 4.0 software (Morris et al., 2009). The three-dimensional crystal structures of HLE were obtained from the Protein Data Bank (PDB IDs: 6F5M) (Hochscherf et al., 2018). The preparation of protein for docking simulations is carried out in the Discovery Studio 4.0 (BIOVIA Discovery Studio 2016). Before molecular docking simulations is started, the potential binding sites of mention proteins are determined using POCASA (POcket-CAvity Search Application). POCASA is an automatic program that implements the algorithm named Roll, which can predict binding sites by detecting pockets and cavities of proteins of known 3D structure. In the case of HLE twelve binding sites are detected and dimensions of the grid boxes for all of them are given in Table 1. The co-crystallized ligand, water molecules, and co-factors are removed from protein structure. Further, in order to add polar hydrogen atoms and to calculate Kollman charges the AutoDockTools (ADT) graphical user interface is used. In molecular docking simulation, the ligand is set as flexible, while the protein remained as a rigid structure. The bonds in ligand are set to be rotatable. The Lamarckian Genetic Algorithm (LGA) method is performed for proteinligand flexible docking simulations. The molecular docking simulation is conducted at a temperature of $298.15 \mathrm{~K}$. Analysis of docking results and visualizations of binding positions are performed by using BIOVIA Discovery Studio. 


\begin{tabular}{|c|c|c|c|}
\hline & $\mathrm{x}$ & $\mathrm{y}$ & $\mathrm{z}$ \\
\hline P1 & 36.4 & 32.6 & 9.9 \\
\hline P2 & 31.5 & 25.4 & 28.5 \\
\hline P3 & 27.7 & 26.5 & 10.2 \\
\hline P4 & 26.1 & 41.1 & 21.7 \\
\hline P5 & 46.6 & 34.0 & 14.1 \\
\hline P6 & 46.1 & 12.8 & 13.4 \\
\hline P7 & 52.5 & 26.4 & 39.3 \\
\hline P8 & 46.6 & 23.1 & 17.5 \\
\hline P9 & 30.8 & 36.4 & 30.3 \\
\hline P10 & 23.6 & 25.3 & 21.3 \\
\hline P11 & 47.6 & 15.0 & 26.2 \\
\hline P12 & 19.9 & 25.6 & 15.0 \\
\hline
\end{tabular}

Table 1. The dimensions of grid boxes for different binding sites of HLE ( $\mathrm{A})$

\section{Results and discussion}

One of the major requirements for phenolic compounds to show antioxidative activity is the formation of a stable phenoxyl radical after free radical scavenging. The reaction enthalpies correlated to above-mentioned antioxidative mechanisms of CYN (HAT, SET-PT and SPLET) are calculated in water and benzene. The preferred antioxidative mechanism can be estimated on the basis of the BDE, IP, and PA values. The lowest values indicate which mechanism is thermodynamically the most favored. The obtained values of thermodynamic parameters that describe antioxidant mechanisms of action are collected in Table 2. From the presented results for calculations achieved in water and benzene (Table 2), it is clear that in both solvents IP values of $\mathrm{OH}$ groups of $\mathrm{CYN}$ are significantly higher than the corresponding BDE and PA values. This fact defines SET-PT mechanism as unlikely reaction pathway for antioxidant action in polar and non-polar solvents. Since the IP values are higher in comparison to BDEs and PAs, SET-PT mechanism will not be further discussed. The obtained values for BDE and PA are different in examined solutions. When the results obtained for BDE and PA in water are compared, it is notable that significant lower values are achieved for PAs. These results indicate SPLET mechanism as favorable mechanism of antioxidant action in water. The analysis of results obtained in benzene give a different picture. Namely, slightly lower values are achieved for BDE in benzene. Based on this fact, it could be said that probable mechanistic pathway of antioxidant action in benzene is HAT, but since PA values are not significantly higher than corresponding BDEs, the best is to conclude that HAT and SPLET are competitive in benzene. In addition, it should be pointed out that BDE and PA values obtained for all hydroxyl group are similar, in some cases the same. This is a consequence of the structure of CYN molecule (Fig. 1). It is notable that methyl group have an insignificant contribution to the antioxidative properties due to its positive inductive effect.

\begin{tabular}{lccccccccccc}
\hline \multicolumn{1}{c}{ Water } & \multicolumn{10}{c}{ Benzene } \\
\cline { 2 - 12 } & HAT & SET-PT & \multicolumn{3}{c}{ SPLET } & \multicolumn{3}{c}{ HAT } & SET-PT & \multicolumn{3}{c}{ SPLET } \\
Site BDE & IP & PDE & PA & ETE & BDE & IP & PDE & PA & ETE \\
& & 506 & & & & & 662 & & & \\
P1 & 387 & & 96 & 211 & 391 & 395 & & 168 & 422 & 409 \\
P2 & 391 & & 101 & 214 & 392 & 401 & & 174 & 428 & 408 \\
P5 & 391 & & 100 & 214 & 392 & 400 & & 172 & 427 & 408 \\
\hline
\end{tabular}




\begin{tabular}{|c|c|c|c|c|c|c|}
\hline P6 392 & 101 & 215 & 392 & 402 & 174 & $428 \quad 408$ \\
\hline
\end{tabular}

Table 2. Calculated reaction enthalpies $\left(\mathrm{kJ} \mathrm{mol}^{-1}\right)$ for the antioxidant reactions of cynodontin

Further is examined the radical scavenging activity in the presence of free radical species. It is known that the scavenging mechanisms of antioxidants are highly influenced by the properties of the scavenged radical species. Three different free radical species were used for calculations: hydroxyl radical $\left({ }^{\circ} \mathrm{OH}\right)$, methyl-peroxyl radical $\left(\mathrm{CH}_{3} \mathrm{OO}{ }^{\bullet}\right)$, and hydroperoxyl radical $\left({ }^{\circ} \mathrm{OOH}\right)$. Hydroxyl and hydrogen-peroxyl radicals are oxygen-derived free radicals included in the complex process of innate immunity and phagocytosis. Their production begins with the activation of NADPH, and their main goal is the destruction of pathogens or other foreign matter. The harmful action of these radicals arises because of some autoimmune diseases when immune cells become over-activated and toxic to neighboring healthy cells. In addition, the ${ }^{\bullet} \mathrm{OH}$ radical is a very powerful oxidant and it is a product of the Fenton and HaberWeiss reaction. This radical can initiate the reaction with hydrocarbons in the presence of air in which peroxyl radicals are produced. The third mentioned is $\mathrm{CH}_{3} \mathrm{OO}{ }^{\bullet}$ radical, and it is used to simulate lipid peroxyl radicals, formed in the metabolic reaction of lipid peroxidation.

\begin{tabular}{|c|c|c|c|c|c|c|c|c|c|c|}
\hline & \multicolumn{5}{|l|}{ Water } & \multicolumn{5}{|c|}{ Benzene } \\
\hline & HAT & \multicolumn{2}{|l|}{ SET-PT } & \multicolumn{2}{|l|}{ SPLET } & HAT & \multicolumn{2}{|l|}{ SET-PT } & \multicolumn{2}{|l|}{ SPLET } \\
\hline & $\Delta_{r} H_{B D E}$ & $\Delta_{r} H_{I P}$ & $\triangle_{r} H_{P D E}$ & $\triangle_{r} H_{P A}$ & $\Delta_{r} H_{E T E}$ & ${ }_{E} \triangle_{r} H_{B D E}$ & $\Delta_{r} H_{I P}$ & $\triangle_{r} H_{P D I}$ & ${ }_{E E} \Delta_{r} H_{P A}$ & $\Delta_{r} H_{E T E}$ \\
\hline & & & & & & & & & & \\
\hline $\mathrm{P}-1+{ }^{\bullet} \mathrm{OH}$ & -107 & & -218 & -104 & -3 & -105 & & -430 & -176 & 71 \\
\hline $\mathrm{P}-2+\bullet \mathrm{OH}$ & -103 & & -214 & -100 & -3 & -99 & & -424 & -170 & 70 \\
\hline $\mathrm{P}-5+{ }^{\bullet} \mathrm{OH}$ & -103 & & -214 & -100 & -3 & -101 & & -425 & -171 & 70 \\
\hline \multirow[t]{2}{*}{$\mathrm{P}-6+\bullet \mathrm{OH}$} & -102 & & -213 & -100 & -2 & -99 & & -423 & -169 & 70 \\
\hline & & 204 & & & & & 405 & & & \\
\hline $\mathrm{P}-1+\bullet \mathrm{OOH}$ & 29 & & -175 & -61 & 90 & 39 & & -366 & -113 & 152 \\
\hline $\mathrm{P}-2+\bullet \mathrm{OOH}$ & 33 & & -170 & -57 & 90 & 45 & & -360 & -106 & 151 \\
\hline $\mathrm{P}-5+\bullet \mathrm{OOH}$ & 33 & & -171 & -57 & 90 & 44 & & -362 & 108 & 151 \\
\hline \multirow[t]{2}{*}{$\mathrm{P}-6+\bullet{ }^{\bullet} \mathrm{OH}$} & 34 & & -170 & -57 & 81 & 45 & & -360 & -106 & 151 \\
\hline & & 211 & & & & & 408 & & & \\
\hline $\mathrm{P}-1+\mathrm{CH}_{3} \mathrm{OO}^{\bullet}$ & 36 & & -175 & -60 & 97 & 47 & & -361 & -108 & 155 \\
\hline $\mathrm{P}-2+\mathrm{CH}_{3} \mathrm{OO}^{\bullet}$ & 41 & & -170 & -57 & 98 & 53 & & -355 & -102 & 154 \\
\hline $\mathrm{P}-5+\mathrm{CH}_{3} \mathrm{OO}^{\bullet}$ & 41 & & -171 & -57 & 97 & 51 & & -357 & -103 & 154 \\
\hline $\mathrm{P}-6+\mathrm{CH}_{3} \mathrm{OO} \bullet$ & 42 & & -170 & -56 & 98 & 53 & & -355 & -101 & 154 \\
\hline
\end{tabular}

Table 3: Calculated parameters of the free radicals scavenger mechanisms for cynodontin $(\mathrm{kJ}$ $\mathrm{mol}^{-1}$ )

The enthalpies of reactants, products, as well as a change of enthalpies of reactions of CYN with selected free radicals, are calculated to take into account the electronic properties of selected free radicals on the reaction of analyzed antioxidative mechanisms. The preferred mechanism is assumed from the $\Delta_{r} H_{B D E}, \Delta_{r} H_{I P}$, and $\Delta_{r} H_{P A}$ values. More negative values indicate a thermodynamically favorable mechanism. The reaction enthalpies are a quantity that can 
successfully contribute to the understanding of the processes between antioxidant species and free radicals. A direct approach to estimate the change of enthalpy of a reaction is to apply the fundamental thermodynamic relationship, i.e., to subtract the enthalpy of reactants from the enthalpy of products. If the reaction is exothermic, it means that the newly formed radical is more stable than the starting one, implying the reaction path is favorable. Otherwise, if the reaction is endothermic, the reaction path is not favored, because the newly formed radical is less stable than the starting one. The calculated changes of enthalpies are presented in Table 3 and indicate that CYN inactivates selected free radicals. First, it should emphasize that in both examined solvents and for all three examined free radical species are obtained positive values of $\Delta_{r} H_{I P}$. This indicates that SET-PT is not the possible scavenging mechanism in any case under investigation, which is in accordance with the thermodynamic results presented in Table 2.

The analysis of obtained values, in both applied solvents, shows that the most reactive ${ }^{\bullet} \mathrm{OH}$ radical can be inactivated with $\mathrm{CYN}$. The results show, that in water, ${ }^{\bullet} \mathrm{OH}$ can be inactivated via HAT and SPLET. Namely, calculated values of $\Delta_{r} H_{B D E}$ and $\Delta_{r} H_{P A}$ in water are similar, which indicates competition between these two mechanisms. On the other hand, calculated reaction enthalpies in benzene show that SPLET is the favorable mechanism of ${ }^{\circ} \mathrm{OH}$ radical scavenging.

Furthermore, if one discusses results obtained for reaction with ${ }^{\bullet} \mathrm{OOH}$ and $\mathrm{CH}_{3} \mathrm{OO}{ }^{\bullet}$, first it should be pointed out that significant lower and negative values are obtained for $\Delta_{r} H_{P A}$ than for $\triangle_{r} H_{B D E}$ in both solvents, water and benzene. This fact indicates that for inactivation of these two radicals SPLET is the dominant reaction pathway of antioxidative action. A comparison of the obtained values indicates that lower values are realized in reactions with ${ }^{\circ} \mathrm{OH}$ radical, which is a consequence of its high reactivity. In addition, the presented values of reaction enthalpies with the abovementioned free radicals one more time confirm that the insignificant lower values are achieved for the hydroxyl group in positions 1 due to the presence of the methyl group.

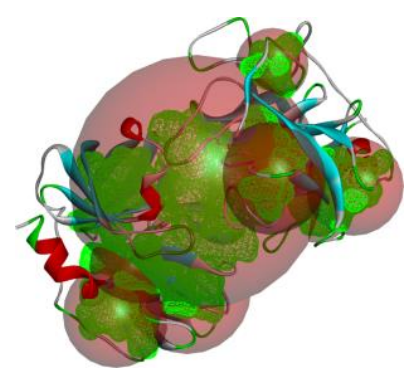

Fig. 2. The representation of the map of bindings sites of HLE

The docking simulations are conducted for all binding sites that POCASA predicted (Fig. 2 ). the analysis of obtained results indicates the binding site $\mathrm{P} 4$ as the most favorable site of binding since the obtained values of binding energy and inhibition constant is the lowest (Table 4). The estimated free energy of binding $\left(\Delta \mathrm{G}_{\mathrm{bind}}\right)$ is $-30.50 \mathrm{~kJ} \mathrm{~mol}^{-1}$, and estimated inhibition constant, $\mathrm{Ki}$ is $4.50 \mu \mathrm{M}$. The value of free energy for binding consists of the Final Intermolecular Energy (FIE), Final Total Internal Energy (FTIE), Torsional Free Energy (TFE), and Unbound System's Energy (USE) (Eq. 23). The FIE is a summary of the Van der Waals energy, energy of hydrogen bonds, desolvation energy of the system, and electrostatic energy. It is worthy to mention that the values of FTIE and USE are the same. Also, it should be pointed out that values of free energy of binding obtained for simulation in binding site P8 are positive, which indicate that binding between CYN and HLE as not probable in that part of protein.

$$
\text { EstimatedFreeEnergyofBinding }=[(F I E)+(F T I E)+(T F E)-(U S E)]
$$




\begin{tabular}{|c|c|c|c|c|c|c|c|c|}
\hline & $\begin{array}{c}\Delta \mathrm{G}_{\text {bind }} \\
\left(\mathrm{kJ} \mathrm{mol}^{-1}\right)\end{array}$ & $\begin{array}{c}\mathrm{K}_{\mathrm{i}} \\
(\mathrm{uM})\end{array}$ & $\begin{array}{c}\mathrm{FIE} \\
\left(\mathrm{kJ} \mathrm{mol}^{-1}\right)\end{array}$ & $\begin{array}{c}\text { HdW + } \\
\text { desolv } \\
\text { Energy } \\
\left(\mathrm{kJ} \mathrm{mol}^{-1}\right)\end{array}$ & $\begin{array}{c}\text { Electrostatic } \\
\text { Energy } \\
\left(\mathrm{kJ} \mathrm{mol}^{-1}\right)\end{array}$ & $\begin{array}{c}\text { FTIE } \\
\left(\mathrm{kJ} \mathrm{mol}^{-1}\right)\end{array}$ & $\begin{array}{c}\text { TFE } \\
\left(\mathrm{kJ} \mathrm{mol}^{-1}\right)\end{array}$ & $\begin{array}{c}\text { USE } \\
\left(\mathrm{kJ} \mathrm{mol}^{-1}\right)\end{array}$ \\
\hline P1 & -20.04 & 306.20 & -25.06 & -24.35 & -0.67 & -10.88 & 4.98 & -10.88 \\
\hline P2 & -21.42 & 177.98 & -26.40 & -26.23 & -0.17 & -11.30 & 4.98 & -11.30 \\
\hline P3 & -19.46 & 389.16 & -24.48 & -24.18 & -0.25 & -11.17 & 4.98 & -11.17 \\
\hline P4 & -30.50 & 4.50 & -35.52 & -34.56 & -0.96 & -10.71 & 4.98 & -10.71 \\
\hline P5 & -22.05 & 138.08 & -27.03 & -26.48 & -0.54 & -10.88 & 4.98 & -10.88 \\
\hline P6 & -15.10 & 2250 & -20.08 & -19.04 & -1.05 & -10.96 & 4.98 & -10.96 \\
\hline P7 & -21.51 & 170.34 & -26.48 & -25.56 & -0.92 & -11.17 & 4.98 & -11.17 \\
\hline P8 & 294.89 & & 289.91 & 291.12 & -1.21 & -5.10 & 4.98 & -5.10 \\
\hline P9 & -11.17 & 11110 & -16.15 & -15.90 & -0.25 & -11.34 & 4.98 & -11.34 \\
\hline P10 & -9.16 & 24780 & -14.14 & -13.51 & -0.63 & -10.96 & 4.98 & -10.96 \\
\hline P11 & -21.00 & 210.33 & -25.98 & -25.69 & -0.29 & -8.41 & 4.98 & -8.41 \\
\hline P12 & -16.82 & 1130 & -21.80 & -21.59 & -0.21 & -11.13 & 4.98 & -11.13 \\
\hline
\end{tabular}

Table 4. Obtained values of energy from docking simulations

As the matter of the value of $\mathrm{K}_{\mathrm{i}}$, the smaller values of the $\mathrm{K}_{\mathrm{i}}$ indicates the greater binding affinity and the smaller concentration of ligand is needed in order to inhibit the activity of receptor. The analysis of results presented in Table 4 shows that values of binding energy and $\mathrm{K}_{\mathrm{i}}$ are in correlation. In the case of position $\mathrm{P} 4$, the lowest values are obtained in both cases. Further will be discussed interactions obtained for complex obtained in grid box named as P4.

In protein-ligand complex obtained for binding site $\mathrm{P} 4$, two types of interactions are present and they form hydrogen bonds and hydrophobic contacts (Fig. 3). Regards hydrogen bonds, it should be pointed out that two types of hydrogen bonds are established: conventional hydrogen bond and carbon hydrogen bond. The lengths of conventional hydrogen bonds are in range $1.64-2.26 \AA$, and they are formed with Leu130, Cys182, Thr165, and Val164 from HLE. Carbon hydrogen bond is formed between Thr165 and Arg129, and lengths of these interactions are 3.03 and $2.74 \AA$. In all these interactions, contacts are made between $\mathrm{H}$-donor and $\mathrm{H}$ acceptor. The other contacts are from the electrostatic and hydrophobic category. The electrostatic contact is $\pi$-cation type of interaction, while hydrophobic contacts are $\pi-\sigma, \pi$ Sulfur, Amide- $\pi$ Stacked, $\pi$-Alkyl, and Alkyl type of interactions. From all accomplished interactions, the most significant are those with Thr165 and Cys182. Those amino acids from HLE form hydrogen bonds in lengths 1.95 and $1.64 \AA$ for Thr165 and Cys182, respectively. The energy of those hydrogen bonds are -6.78 and $-9.74 \mathrm{~kJ} \mathrm{~mol}^{-1}$. 


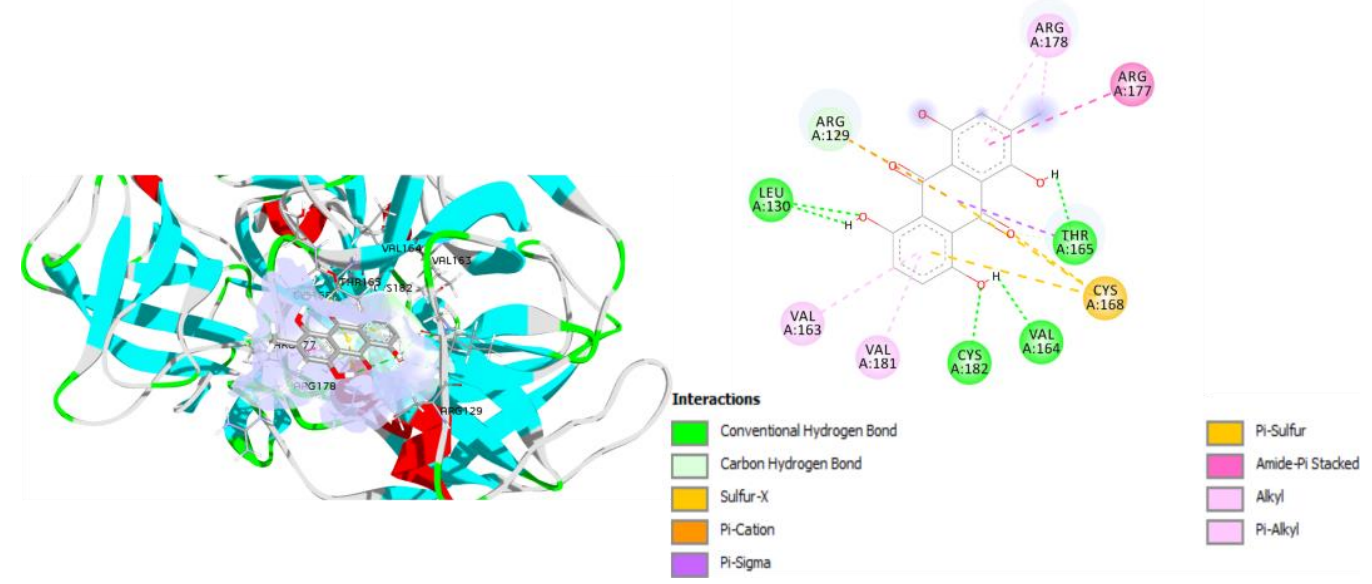

Fig. 3. The best docking positions (P4) of protein-ligand complex

\section{Conclusions}

The antioxidative and inhibitory potency of cynodontin is reported in the present study. The three antioxidative mechanisms of action were investigated. The thermodynamical calculations were performed in polar and non-polar solvents. The antioxidative potency is analyzed based on the results achieved in the absence of free radical species, and in the presence of hydroxyl, and hydroperoxyl and methyl-peroxyl radical. The thermodynamic parameters and reaction enthalpies were calculated to determine the most probable mechanism of antioxidant action. In both cases, and under all investigated conditions, SET-PT mechanism is not the operative mechanism of antioxidant action. The obtained results imply that possible mechanisms of antioxidant action in water is SPLET, while in benzene HAT and SPLET are competitive mechanisms. Regarding scavenging potency of cynodontin of selected radical species, it can be concluded that hydroxyl radical can be scavenged via HAT and SPLET mechanisms in both solvents, while in other two free radical species the only possible scavenging mechanism is SPLET. The molecular docking simulations were performed for cynodontin molecule, and achieved interactions with HLE were carefully examined. The obtained values of free energy of binding and inhibition constant, as well as numerous interactions achieved indicate the inhibition activity towards HLE.

Acknowledgments: This work was supported by the Serbian Ministry of Education, Science and Technological Development (451-03-68/2020-14/200378).

\section{References}

Alberto, M. E., Russo, N., Grand, A., Galano, A. (2013). A physicochemical examination of the free radical scavenging activity of Trolox: mechanism, kinetics and influence of the environment. Physical chemistry chemical physics, 15(13), 4642-4650.

Álvarez-Diduk, R., Galano, A. (2015). Adrenaline and noradrenaline: protectors against oxidative stress or molecular targets? The Journal of Physical Chemistry B, 119(8), 34793491. 
Annen, O., Egli, R., Hasler, R., Henzi, B., Jakob, H., Matzinger, P. (1987). Replacement of disperse anthraquinone dyes. Review of Progress in Coloration and Related Topics, 17(1), $72-85$.

Booth, G. (1988) The Manufacture of Organic Colorants and Intermediates. Society of Dyers and Colourists, UK.

Frisch M. J., Trucks G. W., Schlegel H. B., Scuseria G. E., Robb M. A., Cheeseman J. R., Zakrzewski V. G., Montgomery J. J., Stratmann R. E., Burant J. C., Dapprich S., Millam J. M., Daniels A. D., Kudin K. N., Strain M. C., Farkas O., Tomasi J., Barone V., Cossi M., Cammi R., Mennucci B., Pomelli C., Adamo C., Clifford S., Ochterski J., Petersson G. A., Ayala P. Y., Cui Q., Morokuma K., Malick A. D., Rabuck K. D., Raghavachari K., Foresman J. B., Cioslowski J., Ortiz J. V., Baboul A. G., Stefanov B. B., Liu G., Liashenko A., Piskorz P., Komaromi I., Gomperts R., Martin R. L., Fox D. J., Keith T., Al-Laham M. A., Peng C. Y., Nanayakkara A., Challacombe M., Gill P. M. W., Johnson B., Chen W., Wong M. W., Andres J. L., Gonzalez C., Head-Gordon M., Replogle E. S. and Pople J. A. (2009) Gaussian 09, Revision B.01, Gaussian Inc, Wallingford CT.

Galano, A. (2015). Free radicals induced oxidative stress at a molecular level: the current status, challenges and perspectives of computational chemistry based protocols. Journal of the Mexican Chemical Society, 59(4), 231-262.

Galano, A., Mazzone, G., Alvarez-Diduk, R., Marino, T., Alvarez-Idaboy, J. R., Russo, N. (2016). Food antioxidants: chemical insights at the molecular level. Annual review of food science and technology, 7, 335-352.

Gordon, P. F., Gregory, P. (2012). Organic chemistry in colour. Springer Science Business Media.

Halliwell B., Gutteridge J.M.C. (1999) Free Radicals in Biology and Medicine, Clarendon Press, Oxford.

Halliwell, B. (2001a). Free radicals and other reactive species in disease. Els, 1-9.

Halliwell, B. (2001b). Free radicals and other reactive species in disease. Els, 1-9

Hiemstra, P. S., Van Wetering, S., Stolk, J. (1998). Neutrophil serine proteinases and defensins in chronic obstructive pulmonary disease: effects on pulmonary epithelium. European Respiratory Journal, 12(5), 1200-1208.

Hochscherf, J., Pietsch, M., Tieu, W., Kuan, K., Abell, A. D., Gütschow, M., Niefind, K. (2018). Crystal structure of highly glycosylated human leukocyte elastase in complex with an S2' site binding inhibitor. Acta Crystallographica Section F: Structural Biology Communications, 74(8), 480-489.

Morris, G. M., Huey, R., Lindstrom, W., Sanner, M. F., Belew, R. K., Goodsell, D. S., Olson, A. J. (2009). AutoDock4 and AutoDockTools4: Automated docking with selective receptor flexibility. Journal of computational chemistry, 30(16), 2785-2791.

Petrović, Z. D., Đorović, J., Simijonović, D., Petrović, V. P., Marković, Z. (2015). Experimental and theoretical study of antioxidative properties of some salicylaldehyde and vanillic Schiff bases. RSC Advances, 5(31), 24094-24100.

Renfrew, A. H. M. (1985) Reactive dyes for cellulose: replacement of anthraquinone blues by triphenodioxazines. Rev. Prog. Coloration, 15.

Rimarčík, J., Lukeš, V., Klein, E., Ilčin, M. (2010). Study of the solvent effect on the enthalpies of homolytic and heterolytic $\mathrm{N}-\mathrm{H}$ bond cleavage in p-phenylenediamine and tetracyano-pphenylenediamine. Journal of Molecular Structure: THEOCHEM, 952(1-3), 25-30.

Rose, R. C., Bode, A. M. (1993). Biology of free radical scavengers: an evaluation of ascorbate. The FASEB journal, 7(12), 1135-1142.

Shore, J. (1990). Colorants and auxiliaries.

Sinha, S., Watorek, W., Karr, S., Giles, J., Bode, W., Travis, J. (1987). Primary structure of human neutrophil elastase. Proceedings of the National Academy of Sciences, 84(8), 22282232 . 
Takahashi, H., Nukiwa, T., Yoshimura, K., Quick, C. D., Holmes, M. D., Whang-Peng, J. ...Crystal, R. G. (1988). Structure of the human neutrophil elastase gene. Journal of Biological Chemistry, 263(29), 14739-14747.

Takano, Y., Houk, K. N. (2005). Benchmarking the conductor-like polarizable continuum model $(\mathrm{CPCM})$ for aqueous solvation free energies of neutral and ionic organic molecules. Journal of Chemical Theory and Computation, 1(1), 70-77.

Taylor, G.W., 1986. Natural dyes in textile applications. Review of Progress in Coloration and related topics, 16(1), 53-61.

Thomson, R. H. (1971) Naturally Occurring Quinones, Academic Press, London, New York, 198.

Tošović, J., Marković, S., Milenković, D., Marković, Z. (2016). Solvation enthalpies and Gibbs energies of the proton and electron: influence of solvation models. Journal of Serbian Society for Computational Mechanics, 10(2), 66-76.

Walton, P., Taylor, G. (1991) The characterisation of dyes in textiles from archaeological excavations. Chromatogr. And Analysis.

Zhang, H. Y., Ji, H. F. (2006). How vitamin E scavenges DPPH radicals in polar protic media. New journal of chemistry, 30(4), 503-504.

Zhao, Y., Truhlar, D. G. (2008). The M06 suite of density functionals for main group thermochemistry, thermochemical kinetics, noncovalent interactions, excited states, and transition elements: two new functionals and systematic testing of four M06-class functionals and 12 other functionals. Theoretical Chemistry Accounts, 120(1-3), 215-241.

Zollinger, H. (1987) Synthesis, Properties and Applications of Organic Dyes and Pigments. Colour Chemistry. VCH, Weinheim, New York. 